\title{
Dilatation of the nasal valve by expansion of the vestibular oris (EVO)
}

\author{
Susumu Mukai \\ Otorhinolarynglogy/Maxillofacial Surgery, Mukai Clinic, Yamato, Japan; s-mukai@da2.so-net.ne.jp
}

Received 24 May 2013; revised 26 June 2013; accepted 16 July 2013

Copyright (C) 2013 Susumu Mukai. This is an open access article distributed under the Creative Commons Attribution License, which permits unrestricted use, distribution, and reproduction in any medium, provided the original work is properly cited.

\begin{abstract}
Introduction: The main signs and symptoms of ankyloglossia with deviation of the epiglottis and larynx (ADEL) are sleep disorders caused by respiratory restraint. The author contrived the surgical procedure of correction of the glosso-larynx (CGL) and expansion of the vestibular oris (EVO) for the cure of ADEL. CGL increases vital capacity (VC) and forced expiratory volume in 1 second (1\% FEV). EVO reduces nasal airflow resistance. The most important component of nasal airflow resistance is the nasal valve. Purpose: Our purpose was to measure how wide the nares were dilated after EVO. Method: The width of the nares, height of the nose, length of the philtrum and width of the lip were measured in patients who had signs and symptoms of ADEL, before and after EVO. Result: Significant increases were observed in the width of the nares, height of the nose and length of the lip after EVO. Conclusion: This study confirmed that the nares dilate after EVO. Not only the amelioration of nasal respiration by EVO increases immunity, but also aesthetic effects are obtained after EVO.
\end{abstract}

Keywords: Respiration; Sleep; Ankyloglossia with Deviation of the Epiglottis and Larynx (ADEL); Nasal Valve; Depressor Septi Nasi Muscle; Nasal Valve

\section{INTRODUCTION}

As we previously reported, the signs and symptoms of ankyloglossia with deviation of the epiglottis and larynx (ADEL) are excessively varied from newborn babies to adults. Common signs and symptoms in adults are insomnia, fatigue, daytime sleepiness, cold hands and legs,

*This study was reported at the $36^{\text {th }}$ WMTS and the Conference of Sports and Preventive Medical Society, Malta, on October 17, 2006. dry skin, stiff shoulders and sleep apnea. Children with ADEL sleep shallow, enuresis and wake up at night, snore and roll about while sleeping are grumpy when they wake up, they have dull complexion are short-tempered, and fall easily. Babies with ADEL cry hard and have colic, wake up easily, have harsh respiratory sounds, suffocate while suckling, sleep while suckling, swallow air while suckling, perform digit sucking, and hurt their mothers' nipples [1-7]. The author contrived the surgical procedure of correction of the glosso-larynx (CGL) and expansion of the vestibular oris (EVO) for the cure of ADEL $[8,9]$.

In patients who underwent CGL and EVO, the multiple signs and symptoms of ADEL disappeared and/or showed dramatic improvements $[8,10]$. Physiological changes induced by CGL include increases in vital capacity (VC) and forced expiratory volume in 1 second (1\% FEV) [11]. The physiological change induced by EVO was a decrease in nasal airflow resistance [12].

EVO is an operation that detaches the depressor septi nasi (DSN) muscle from the maxillary bone between the two canine teeth as high as the piriform edge and the junction of the nasal septum. The author's aim on EVO was that the lateral growth forces of the mandible bone increase and the nasal cavity widens by EVO. As a result, nasal airflow resistance decreases. Unexpectedly, the EVO extended the nasal valve but does not touch the ala nasi as well.

Changes in the nares and influences to the face as a result of detaching the depressor septi nasi (DNS) muscles from the maxillary bone were studied in this report.

\section{PROCEDURE OF EXPANSION OF THE VESTIBULAR ORIS (EVO)}

A $1 \%$ lidocaine injection is administered into the upper vestibular space between the canine teeth.

The incision is started at the attachment of the upper frenulum (Figure 1(a)) and is then expanded from the upper vestibular oris to the level of the junction of the 
nasal septum and the base of the piriform anterior aperture, detaching the depressor septi nasi (DSN) muscle from the maxillary bone between the canines (Figure 1(b)). The EVO procedure is then completed in the open wound.

\section{CASES AND METHOD}

\subsection{Subjects}

The subjects were patients who had signs and symptoms of ADEL, such as sleeping disorders, fatigue, daytime sleepiness, snoring, stiffness of shoulders, cold extremities, and dry skin, and who were scheduled to undergo EVO. There were a total of 73 cases ( 37 males and 36 females), and their age ranged from 19 to 63 years old $(37.9 \pm 14.66$ years old, mean \pm standard deviation).

\subsection{Measured Items}

The lengths of the following items were measured be-

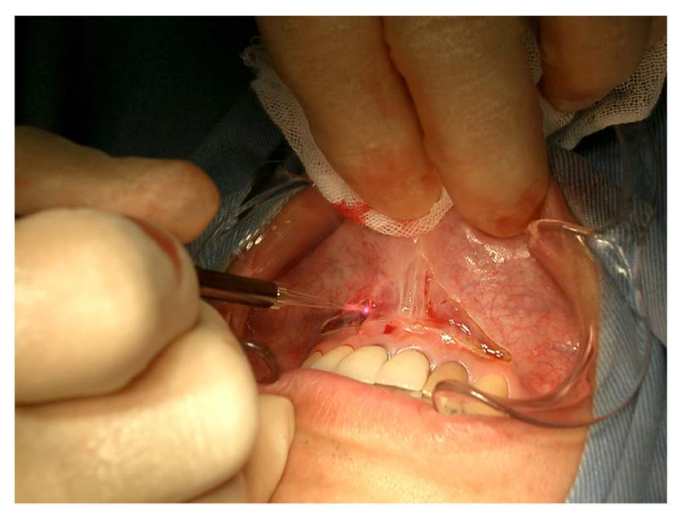

(a)

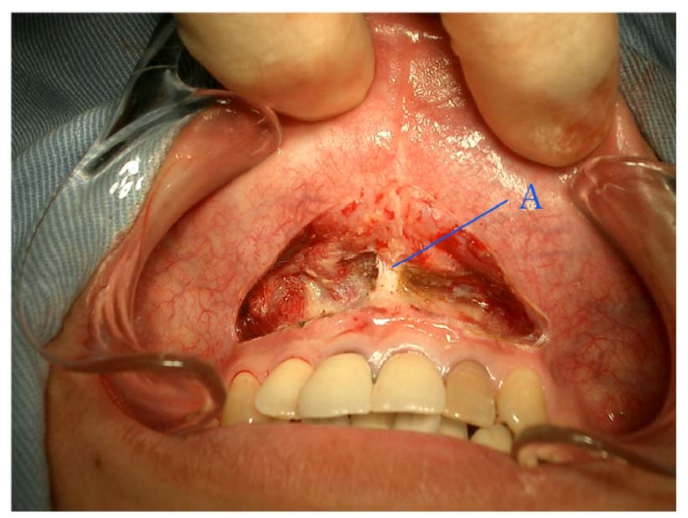

(b)

Figure 1. EVO. (a) The incision is started at the attachment of the upper frenulum. The incision is expanded from the upper vestibular oris to the junction of the nasal septum and the base of the piriform anterior aperture, detaching the DSN (depressor septi nasi muscle) from the maxillary bone between the two canines; (b) View after EVO is completed with the open wound (A, ligament of septal cartilage and maxillary bone). fore and after EVO (Figure 2).

A. Width of the nares: Distance between the longest inside edges of both nares.

B. Height of the nose: distance from the top of the nose to the base of the nose (the top of the philtrum).

C. Philtrum: Length of the philtrum

E. Length of the lip: Distance between the anguli oris.

A stainless-steel straight $15 \mathrm{~cm}$ ruler $(0.5 \mathrm{~mm}$ graduated) and inside caliper (Shinwa Measuring Tool Co., JIS (JQA JQCN08004) were employed to measure the length of each item (Figure 3). The parameters were compared by the paired t-test.

Microsoft Excel was used for statistical analyses. Statistical significance was set at $p<0.1$ in this clinical study.

\section{RESULTS}

The mean parameters in the 73 subjects before and af-

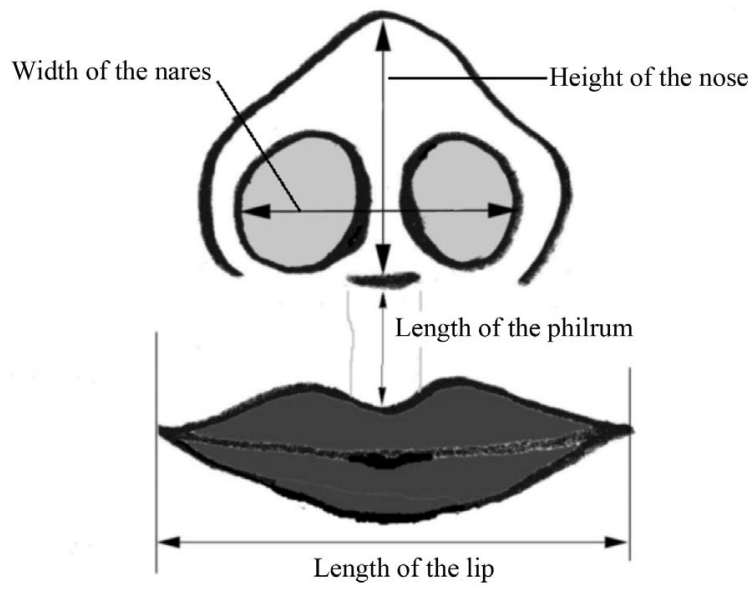

Figure 2. Diagrams of Measured items. 1) Width of the nares: Longest distance between the inside edges of the two nares. 2) Height of the nose: distance from the top of the nose to the base of the nose (the top of the philtrum). 3) Philtrum: Length of the philtrum. 4) Length of the lip: Distance between the two anguli oris.

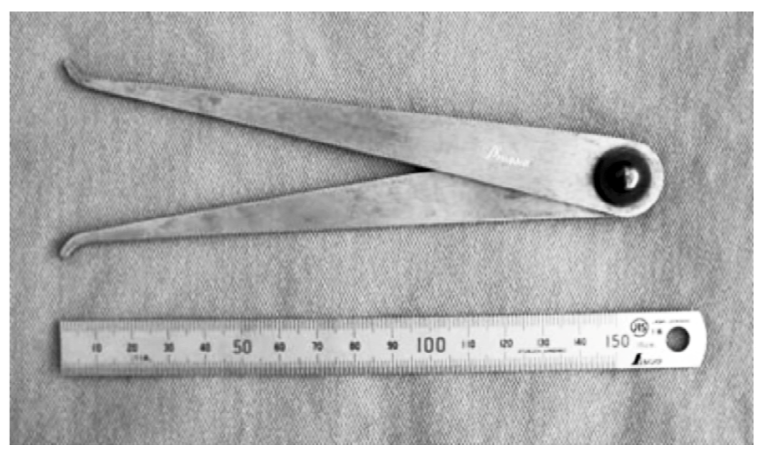

Figure 3. Measuring tools. (Upper) Inside caliper (Shinwa Rules Co. Sanjo, Japan). (Lower) Stainless straight scale (min. unit; $0.5 \mathrm{~mm}$ ) (JIS QNC08004) (Shinwa Rules Co. Sanjo, Japan). 
ter EVO were as follows: the width of the nares changed from $26.2 \mathrm{~mm}$ to $29.9 \mathrm{~mm}(\mathrm{p}=0.00056)$, height of the nose changed from 18.1 to $19.1(\mathrm{p}=0.07244)$, the length of the philtrum changed from 16.4 to $17.1(\mathrm{p}=0.32488)$, and the length of the lip changed from 53.8 to $56.1(\mathrm{p}=$ 0.0244) (Figures 4-6).

Significant differences were observed in the width of the nares, height of the nose and length of the lip.

\section{DISCUSSION}

The most important portion in nasal airflow resistance is the nasal valve. The nasal valve consists of the caudal border of the upper lateral cartilage, the head of the inferior turbinate, the floor of the nose and the nasal septum $[13,14]$.

Cole reported that the main airflow regulator in the (leptorrhine) nose of Caucasians is the nasal valve. In the (platyrrhine) nose of Africans, the main airflow regulator is the turbinal valve. However, Ohki et al. reported that the airflow resistance effect of decongestion of the tur-

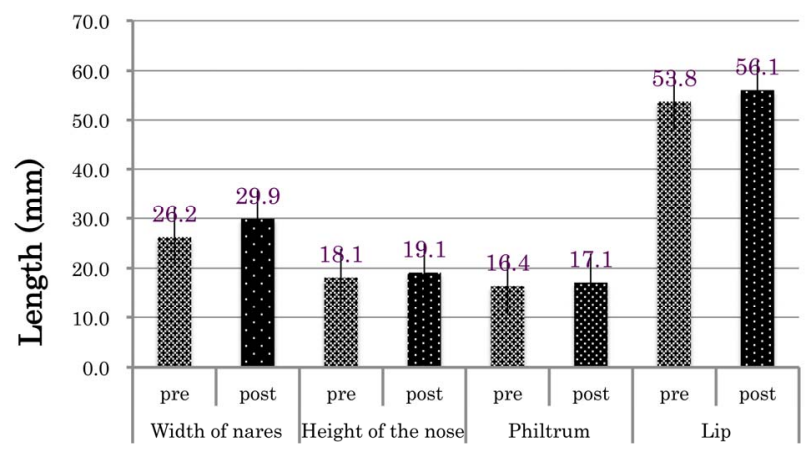

Measured Items

Figure 4. Changes of the measured items (NOTE: How do you think about changing the underlined title to, "Comparison of measured parameters before (pre) and after (post) EVO"). Results are shown as mean and standard deviation $(n=73)$. Significant increases were observed in the width of the nares, height of the nose and length of the lip after EVO. (NOTE: Do you think it's better to write the 4 p-values in the graph itself?).

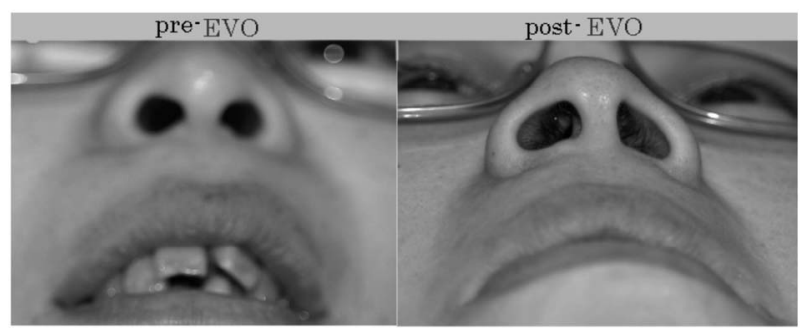

Figure 5. Images of the nose of a patient before (left) and after EVO (right). The patient's nostrils were round and narrow before EVO. After EVO, her nostrils expanded laterally, and the height of the nose increased as well. She kept her mouth open before EVO, but after EVO she closed her mouth and could breathe through her nose.

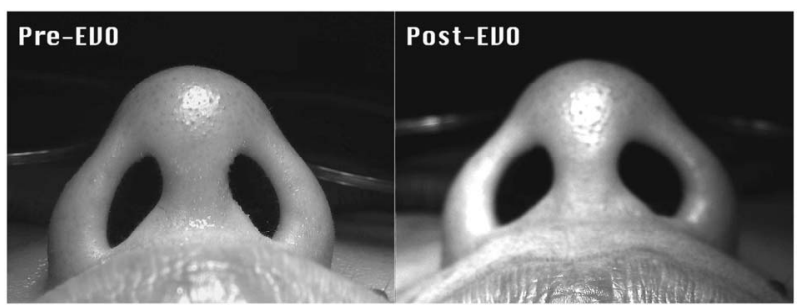

Figure 6. Changes in a nose after EVO. (39-year-old, Caucasian male). His nostrils opened wider after EVO. Before EVO, he snored when he slept. After EVO, he experienced no snoring. In Caucasians the angle between the septum and caudal border of the upper lateral nostril is acute (the average is fifteen degrees). This acute angle of the nostrils is also a cause of snoring.

binates in leptorrhine and platyrrhine noses did not demonstrate significant differences [15-20].

Several surgeries for widening of the nasal valve were reported. In these, procedures were surgically widened the nasal valve by expanding ala nasi themselves. These surgeries are invasive to the nose [21-25]. They have several disadvantages including the following:

1) The operation field is narrow and deep.

2) Experience and skill are required to perform the surgery.

3) Nasal obstruction is inevitable after surgery.

4) Postoperative adhesion of the wound may occur.

The EVO procedure was extended to the nasal valve but did not touch the ala nasi, and is less invasive.

EVO has the following advantages:

1) There is no surgical invasion to the nasal cavities and ala nasi.

2) As the operation is performed on the upper vestibular oris, the surgical field is wide and superficial.

3) Local anesthesia and hemostasis are easily accomplished.

4) The operation time is within ten minutes.

5) The patient can breathe via the nose during the surgery.

6) The patients observed that their breathing became easier just after EVO.

7) Post-operative pain is minimal and wound management is easy.

8) EVO can be performed on babies and adults.

The DSN muscle originates from the incisive fossa of the maxilla, and its fibers extend upward to be inserted into both the septum and the posterior part of the ala of the nose. The origin of the DSN muscle lies beneath the orbicularis oris.

The DSN muscle narrows the nostrils by inhibiting the ala nasi and dilator naris muscles. The DSN muscle shortens the length of the philtrum, resulting in a short distance from the nose to the upper lip. As a result, the upper lip is thinner than the lower lip. It reduces the angles of the lip [26,27]. 
The thickest part of the DSN muscle is between the canine teeth. In some cases, by the author's observation, the depth of the muscle is about $10 \mathrm{~mm}$ from the vestibulum surface at the fosse myrtiform. It lies deepest in the center of the facial muscles and is particularly large compared with the mimic muscles. The DSN muscle inhibits nasal expanders such as the nasal muscles and ala nasi muscles. It shrinks the nares. It also inhibits levator labii superioris muscles, zygomaticus muscles and risorius muscles. As a result, it causes sagging of ala nasi and anguli oris. In addition, the DSN muscle inhibits the activities of the buccinators and zygomaticus major and minor. By the author's observations, a person whose DSN muscle is well developed has narrow nostrils and lip. These suggest that he or she has poorly developed maxillary and mandibular bones compared with his or her developmental cranium. In conclusion, the DSN muscle depresses respiration and is responsible for sad facial expressions. As this study lacks objective data on airflow resistance and /or volume of the nasal valve, comments from patients who underwent EVO are described as follows:

1) Much air enters the nose.

2) Cold air enters deep in the nose.

3) Before the operation, I could not sleep due to coughing when I was in the supine position. Now I can sleep in the supine position without coughing.

4) I got out of breath and felt throbbing when I climbed the stairs. I was surprised that these symptoms disappeared just after the EVO.

5) I had wrinkles on the upper lip when I laughed. The wrinkles disappeared and my nose was wider after the operation.

6) I have a good appetite and everything tastes good. My headaches occur much less frequently.

7) I got a good posture.

8) I have more strength at my job.

9) I feel like I can start something new.

10)I can sleep well in the supine stretched position.

11)I could not smile before but I can smile with my lips after EVO.

The subjective comments after EVO confirm the effectiveness of the surgery.

\section{REFERENCES}

[1] Mukai, S., Mukai, C. and Asaoka, K. (1991) Congenital ankyloglossia with deviation of the epiglottis and larynx. Annals of Otolaryngology, 100, 1-20.

[2] Mukai, S., Mukai, C., Asaoka, K., et al. (1992) Postoperative changes in infant with ADEL (in Japanese with English abstract). Zetuyuchalushou Kenkyuukai Kaiho (Annals ADEL), 1, 35-45.

[3] Mukai, S., Mukai, C., Asaoka, K. and Nagasugi, S. (1992)
Digit sucking. Lancet, 339, 1545-1546. doi:10.1016/0140-6736(92)91316-Z

[4] Mukai, S., Mukai, C. and Asaoka, K. (1993) Congenital ankyloglossia with deviation of the epiglottis and larynx: Symptoms and respiratory function in adult. Annals of Otolaryngology, 102, 620-624.

[5] Mukai, S., Mukai, C., Asaoka, K. and Nagasugi, S. (1994) Nearmiss for sudden infant death syndrome seen in infants who have ankyloglossia with deviation of the epiglottis and larynx (in Japanese). Zetuyuchakusho Kenkyuukai Kaihou (Annals ADEL), 4, 156-167.

[6] Mukai, S, Nagasugi, S. and Higashino, Y. (1997) Sound analysis through subject evaluation of colic crying - First report (in Japanese). Jpn J Logop Phoniatr, 38, 1-10. doi:10.5112/jilp.38.1

[7] Mukai, S. and Nagasugi, S. (1999) Sound analysis through subject evaluation of colic crying-Second report: Colic. Jpn J Logop Phoniatr, 40, 349-356. doi:10.5112/jilp.40.349

[8] Mukai, S. and Nitta, N. (2004) Expansion of the vestibular oris (EVO) (in Japanese). Annals of Ankyloglossia with Deviation of the Epiglottis and Larynx, 12, 1-9.

[9] Nitta, M. and Muka, S. (2004) Hight of nose, ala nasi and lips widen by expansio of vestibular oris (EVO) (in Japanese). Annals of the Ankyloglossia with Deviation of the Epiglottis and Larynx, 12, 10-4.

[10] Mukai, S. and Nitta, M. (2002) Correction of the glossolarynx (CGL) and resultant positional changes of the hyoid bone and cranium. Acta Oto-Laryngologica (Sweden), 122, 644-650. doi:10.1080/000164802320396330

[11] Mukai, S. and Yamamoto, I. (2010) Patial genioglossectomy leading to an increase in respiratory rate-Surgery for ankyloglossia with deviation of the epiglottis and larynx. Nihon Zetuyuchalusho Gakkaishi (Annals ADEL), 16, 5-31.

[12] Mukai, S. (2010) Expansion of the vestibular oris (EVO) -Esthetic facial changes and expansion of the nasal cavity. Nihon Zetuychakusho Gakkai Kaishi (Annals ADEL), 16, 32-41.

[13] Bridger, G.P. (1970) Physiology of the nasal valve. Archives of Otolaryngology, 92, 543-553. doi:10.1001/archotol.1970.04310060015005

[14] Wexler, D.B. and Davidson, T.M. (2004) The nasal valve: A review of the anatomy, imaging, and physiology. American Journal of Rhinology, 18, 143-150.

[15] Cole, P. (1997) Nasal airflow resistance: A survey of 2500 assesment. American Journal of Rhinology, 11, 415-419. doi:10.2500/105065897780914901

[16] Cole, P. (200) The four components of the nasal valve. American Journal of Rhinology, 17, 107-110.

[17] Cottle, M.H. (1955) The structure and function of the nasal vestibule. Archives of Otolaryngology, 62, 173-181. doi:10.1001/archotol.1955.03830020055011

[18] Heinberg, C.E. and Kern, E.B. (1973) The cottle sign: An aid in the physical diagnose of nasal airflow disturbances. 3rd Congress of the International Rhinologic Society, Bordeaux, 89-94. 
[19] Ohki, M. (1991) Dimensions and resistances of the human nose: Racial differences. Laryngoscope, 101, 276278. doi:10.1288/00005537-199103000-00009

[20] Ohki, M. and Hasegawa, M. (1986) Studies of transnasal pressure and airflow in a Japanese population. Rhinology, 24, 277-282.

[21] Paniello, R.C. (1996) Nasal valve suspension: An effective treatment for nasal valve collapse. Archives of Otolaryngology, 122, 1342-1346. doi:10.1001/archotol.1996.01890240050011

[22] Toriumi, D.M., Josen, J., Weiberger, M. and Eugene Tardy, M. (1997) Use of alar batten grafts for correction of nasal valve collapse. Archives of Otolaryngology, 123, 802-808. doi:10.1001/archotol.1997.01900080034002

[23] Sciuto, S. and Bernardeschi, D. (1999) Upper lateral cartilage suspension over dorsal grafts: A treatment for in- ternal nasal valve dynamic incompetence. Facial Plastic Surgery, 15, 309-316. doi:10.1055/s-2008-1064332

[24] Rhee, J.S., Poetker, D.M., Smith, T.L., et al. (2005) Nasal valve surgery improves disease-specific quality of life. Larygoscope, 115, 437-440. doi:10.1097/01.mlg.0000157831.46250.ad

[25] Khosh, M.M., Honrado, C. and Peariman, S.J. (2004) Nasal valve reconstruction. Archives of Facial Plastic Surgery, 6, 167-171.

[26] Rouviére, H., Delmas, A., du Nez, M. and des Léves, M. (2002) Anatomie humaine, Descriptive, topographie et fonctionelle. MaSSON, Paris, 172-179.

[27] Figallo, E.E. and Acosta, J.A. (2001) Nose mascular dynamics: The tip trigonum. Plastic \& Reconstructive Surgery, 108, 1118-1126. doi:10.1097/00006534-200110000-00003 